\title{
An Analysis of the Sustainable Development Path of China's New Government Affairs Media from the Perspective of Science and Technology Innovation
}

\author{
Rui Wang ${ }^{1 *}$ \\ ${ }^{1}$ Department of Media and Art Design, Huali College of Guangdong University of Technology, Guangzhou, Guangdong Province, 511325 \\ China
}

\begin{abstract}
The Chinese government actively uses the new media platform to disseminate government information and provide government services. Contemporary scientific and technological innovation, with computers and information science and technology as engines, has become the core driving force of "leading development". This article puts the new media of Chinese government affairs under the perspective of technological innovation, analyzes the bottlenecks and possible solutions it faces, discusses the sustainable development path of new media for Chinese government affairs, and strive to provide some reference for the sustainable development of new media for government affairs in other countries or regions.
\end{abstract}

\section{Overview of the development of new media for Chinese government affairs}

New media for government affairs is a brand-new method of communication derived from the rapid development of information technology, refers to the relevant applications and government accounts opened on third-party platforms such as WeChat, Weibo. under the circumstances of fully considering the overall management and development needs of administrative agencies at all levels, public institutions that undertake administrative functions, and their internal institutions, or according to different Mobile client requesting self-development and construction ${ }^{[1]}$.

2011 is the first year of China's "government microblog" and the first year of China's new media for government affairs. According to statistics, as of December 2016, there were 165,000 government microblogs nationwide, and the number of online government service users reached 239 million, and 30\% of netizens used online government services ${ }^{[2]}$.

In 2019, after the initial freshness and enthusiasm receded, China's new media for government affairs ushered in a wave of shutdowns. After this wave of rectification, China's new media for government affairs gradually got rid of the initial bad development trend, and all parts of the country have accelerated the construction of digital government. In November 2019, the national integrated online government affairs platform was put into trial operation, and a substantial step was taken to promote the government affairs service "One Netcom Office" ${ }^{[3]}$.

On April 28, 2020, CNNIC released the 45th "Statistical Report on China Internet Development Status. The data shows that as of March 2020, my country's online government service users reached 694 million, an increase of $76.3 \%$ from the end of 2018 , accounting for $76.8 \%$ of the overall Internet users ${ }^{[4]}$. In early 2020 , a new coronary pneumonia outbreak, China's new media for government affairs has played an important role in slowing down the provision of epidemic information services, the implementation of online government affairs management, and the promotion of precision epidemic prevention.

\section{Analysis of Problems Faced by New Media for Chinese Government Affairs}

From 2011 to 2020, China's new media for government affairs has gone through nearly ten years. Great achievements have been made. But at the same time, there are still a series of problems.

\subsection{Lack of top-level design}

Despite the integration of information resources, the development level of new media for government affairs in various regions and departments varies greatly. Many regions and departments have not made an overall and long-term plan for the layout of new government affairs media, and some new government affairs media still have problems such as function convergence, content duplication, and weakened services. The lack of resource integration and scientific layout in the construction of new media for government affairs will inevitably lead to redundancy in quantity and inferior quality, and it will not be able to effectively play the advantages of cluster linkage. 


\subsection{Absence of operation management}

Local government affairs new media generally have the problem of lack of operation management team, which is mainly reflected in the small number of operating personnel, unprofessional, lack of necessary copywriting planning and information collection and editing expertise, and related experience of operating new media, which makes content production difficult and operation A series of problems such as high personnel pressure, weak communication power, and weak social credibility.

\subsection{Inaccurate media positioning}

After the first government affairs microblog was born, government departments at all levels and all levels of the country created their own government accounts on Weibo. However, in addition to having an officially certified identity, many government microblogs do not have a clear and accurate positioning in terms of operation management and content production. In addition, the lack of professionally qualified operation teams often just blindly forward some work with the government. Unrelated articles, leading to weakened or missing government functions.

\subsection{Insufficient service capacity}

Now that the new government affairs media has become the standard configuration of the party committees and government departments, the functions of government affairs disclosure and service interaction of some new government affairs media are far from being able to meet the increasing diversified needs of netizens due to the limited breadth and depth of expansion. Development model to improve service capabilities.

\subsection{Weak content production}

Even in the new media era, "content is king" is still the guideline for information production. What the media has long used to attract and maintain the audience, build media credibility and build brand loyalty can only be information content of excellent quality. For many new government affairs media, content production is their "short board", resulting in very few original content, blind forwarding, hard copying, and poor timeliness.

\section{Favorable conditions for sustainable development of China's new media for government affairs from the perspective of technological innovation}

\subsection{The Development of New Media for Chinese Government Affairs from the Perspective of Science and Technology Innovation}

Relying on the rapid development of computer and information science and technology, contemporary technological innovation has achieved rapid development, and has become the core driving force for the development and progress of various social undertakings. For the new media industry that also relies on computers and information science and technology, in order to break through the "bottleneck" and achieve sustainable development, technological innovation deserves greater attention and attention. New media for government affairs, because its sponsor is the government, has inherent advantages in politics, economy, and systems. It should also firmly grasp the "weapon" of technological innovation and continue to seek innovative development paths.

\subsection{Solid foundation for development}

The term "sustainable" is derived from the Latin word "sustenere", which means "maintain and continue to improve"[5], The rapid development of China's high-tech industry, the demand driven by media audiences, and the government's inclusive support all provide guarantees for the sustainable development of new government media.

The 45th "Statistical Report on Internet Development in China" shows that as of March 2020, the scale of Chinese Internet users was 904 million, and the Internet penetration rate reached $64.5 \%$. Among them, the number of mobile Internet users is 897 million, and the proportion of Internet users using mobile phones to access the Internet is $99.3 \%$.

As a large country with a population of 1.4 billion, China has a huge netizen population and high Internet penetration and usage. In particular, mobile terminals, which are the main receiving tools of new media information, have large mobile Internet users, which provides user protection for the sustainable development of new media.

In addition, China's new media also has the convenience of having established user loyalty. According to statistics, as of March 2020, the per capita online time of Chinese netizens is 30.8 hours per week.

\subsection{Changes in Internet communication}



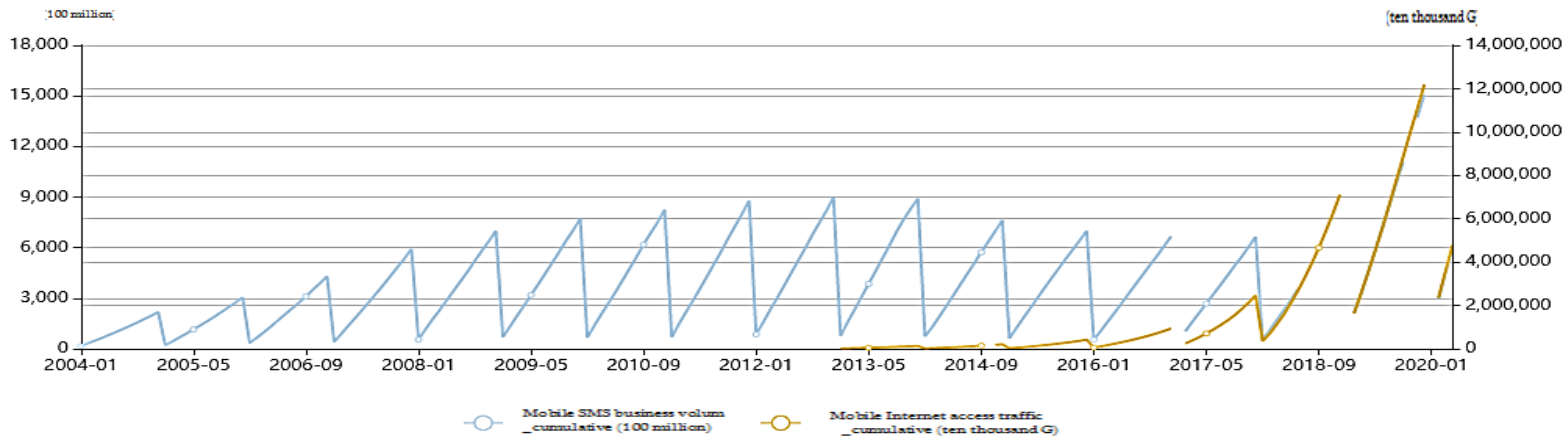

Fig1. Comparison of mobile short message service and mobile Internet access traffic from 2004 to 2020

It can be seen from Figure 1 that from January 2004 to mid-2017 in China, the volume of short-message communication services accounted for mainstream communication consumption. Mobile Internet intervention traffic has been growing slowly from the end of 2012 to 2017 . From 2017 to the present, mobile Internet intervention traffic has shown rapid growth. Flow rate billing is more economical than the SMS business cost is the main reason for this situation.

\subsection{The rapid development of communication services}

China's domestic mobile, China Unicom, telecommunications and other communication operators have gradually improved infrastructure, and have planned to invest in 5G. communication methods to provide better service quality for domestic communication end users. The terminal software is rich in content, and the income from software business information technology services shows a rising trend.

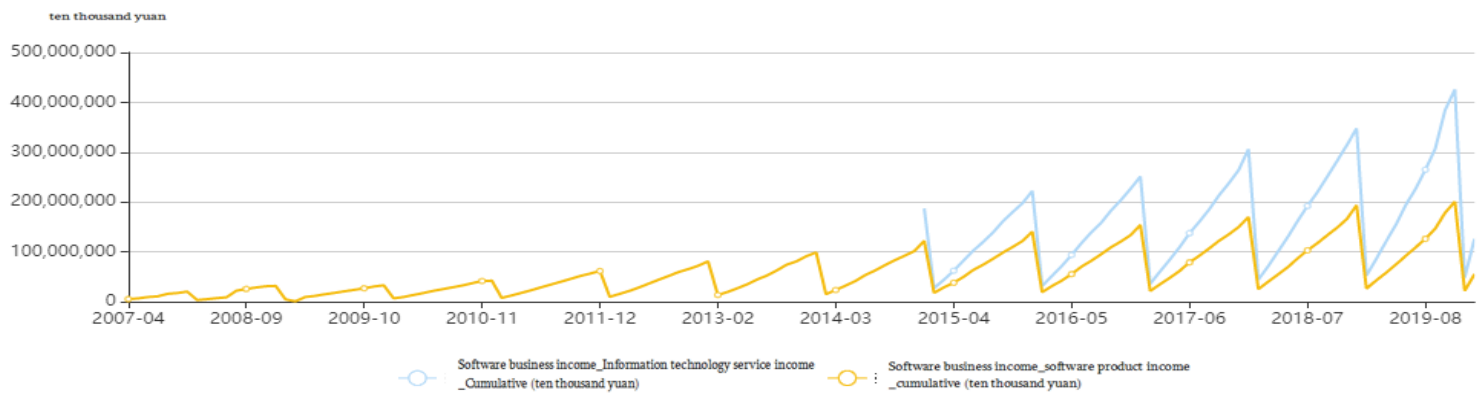

Fig2. 2007-2019 China Software Revenue Chart

\section{An Analysis of the Sustainable Development Path of New Government Affairs Media}

\subsection{Strengthening the top-level design of new media for government affairs}

To maintain healthy operation of the new media for government affairs, a scientifically designed performance appraisal and evaluation system is needed for testing and standardization. The ruling model of "Internet + government affairs" based on the new media platform is inseparable from the top-level planning and design of government departments. On the basis of deep understanding of the characteristics of new government affairs media, a scientific quantitative evaluation system should be established, multiple factors work together to continuously improve, and effectively improve the service and interaction of new government affairs media, in order to create openness, convenience and equality The new system of government affairs communication.

\subsection{Government new media platform operation and maintenance}

The government began to cooperate with traditional media to jointly operate and maintain the new media for government affairs. Based on the technical advantages of high-speed information dissemination and in-depth interaction in new media, the government, the media, and the public have shown a deep integration.

\subsection{Building a new media matrix for government affairs}

Strengthening the construction of the matrix and enhancing the online service capabilities are proven 'good recipes' for promoting the sustainable development of new media for government affairs. For example, in May 2019, Jingbao integrated more than 140 new government affairs media in its own operation and maintenance into an App to form a larger-scale matrix system ${ }^{[6]}$.

The new media matrix for government affairs can 
effectively integrate the information release resources of all relevant aspects, and achieve the two-way superposition effect of the integration of government affairs and media.

\subsection{Pay attention to public demands and form benign interactions}

The government moved government affairs to the Internet, released information and provided online government affairs services through new government affairs media, and these activities ultimately pointed to the public. While the public accepts information and services, it can also provide feedback on government affairs information and services at any time through the new government affairs media to help the government and the operation and maintenance parties find the best communication method and continuously revise the various functions of the new government affairs media. And improvements.

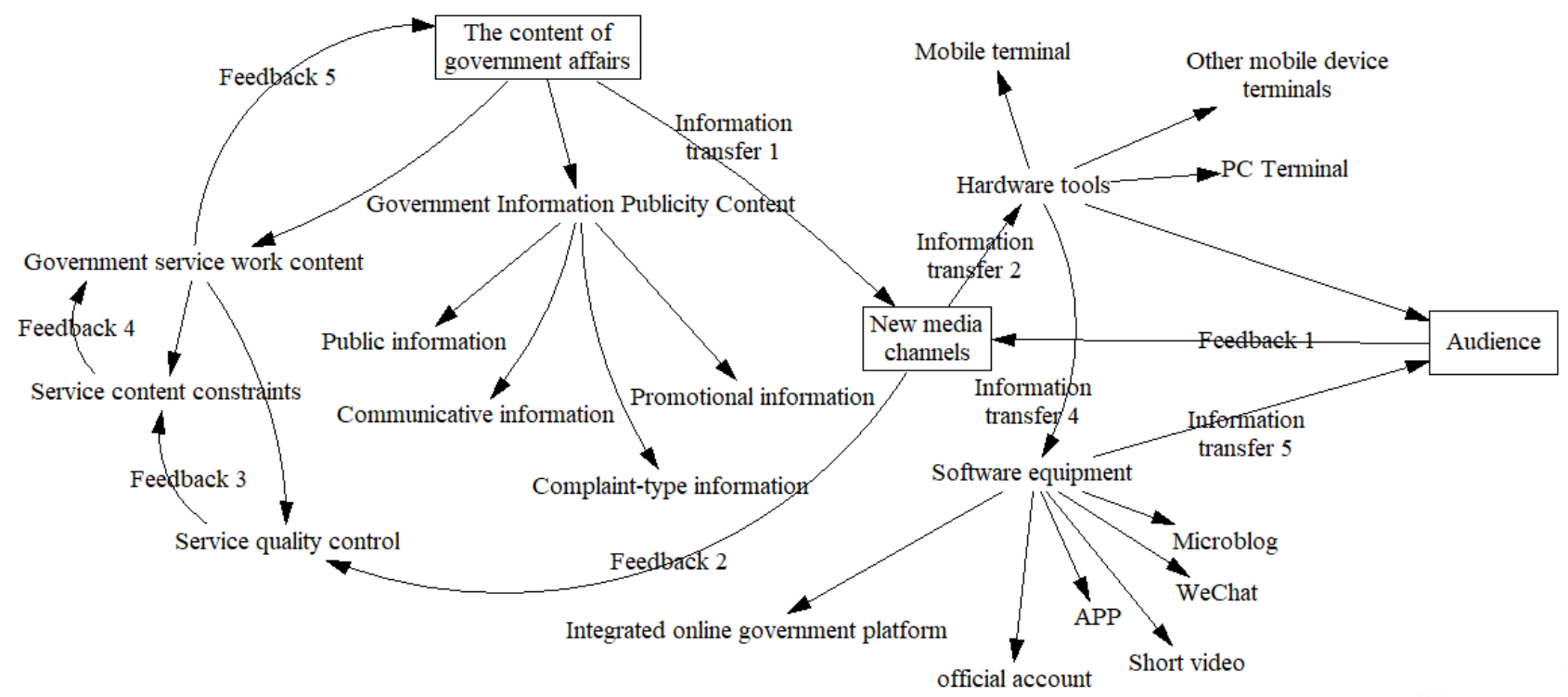

Figure 3 Schematic diagram of sustainable development of new government media academic studies.

I also owe a special debt of gratitude to my friend An

\section{Conclusion}

In order to achieve sustainable development, China's new government media needs to firmly establish the concept of technological innovation, put the three elements of government, media, and the public in the same system, integrate them from a system perspective, and increase the breadth and depth of its integration. Government departments lead the construction and operation and maintenance of new media, through scientific and rational top-level design, establish effective performance evaluation and reward and punishment mechanisms, and promote the establishment of a government new media matrix. At the same time, it is necessary to fully consider the needs of the public, pay attention to the status and role of the public in the process of government information dissemination and government services, and form an effective feedback loop to achieve healthy, stable, and sustainable development. This type of new media for government affairs is conducive to creating a smart government and promoting the continuous improvement of the level of social governance.

\section{Acknowledgment}

I would like to express my gratitude to all those who helped me during the writing of this thesis. I gratefully acknowledge the help of my predecessor, professor Niu Lihong, who has offered me valuable suggestions in the
Mingming for her inspiration and encouragement in my scientific research work.

Finally, I should finally like to express my gratitude to my beloved parents and my wife, my son.

\section{References}

1. Cao,S.Y.(2020)Analysis of the development status, existing problems and countermeasures of new media for government affairs. JOURNAL OF NEWS RESEARCH, 03:150-152.

2. Ma, C, X.Liang, C.H.(2020) Research on the Development Path of New Media for Education and Government Affairs in Henan Province. JOURNALISM LOVER.05: 88-90.

3. Zhu, X, N.(2017)The Construction of Local "Double Micro" Government Affairs Communication System-Based on the Observation of the Five Main Functional Areas of Liaoning Province. MEDIA. 24:58-62.

4. CNNIC.(2020)The 45th "Statistical Report on Internet Development in China".http://www.cac.gov.cn/202004/27/c_1589535470378587.htm.

5. Ma, J, Y.(2018)Park planning and design. China Agricultural University Press. BeiJing.

6. Chen, X, Y.(2020)The Difficulties of Operation and Maintenance of New Media for Local Government 
Affairs and the Way to Breakthrough-Taking Jingbao "Sunshine" Government New Media Matrix. YOUNG journalist.12:62-63 